\title{
Feasibility of implementing systematic social needs assessment for children with medical complexity
}

\author{
David Y. Ming ${ }^{1,2,3^{*}} \mathbb{D}$, Kelley A. Jones ${ }^{3}$, Elizabeth Sainz ${ }^{1}$, Heidie Tkach ${ }^{4}$, Amy Stewart ${ }^{4}$, Ashley Cram5, \\ Madlyn C. Morreale ${ }^{4,6}$, Samantha Dizon ${ }^{1,2}$ and Neal A. deJong ${ }^{4}$
}

\begin{abstract}
Background: Children with medical complexity (CMC) have inter-related health and social needs; however, interventions to identify and respond to social needs have not been adapted for CMC. The objective of this study was to evaluate the feasibility of implementing social needs screening and assessment within pediatric complex care programs.

Methods: We implemented systematic social needs assessment for CMC (SSNAC) at two tertiary care centers in three phases: (1) pre-implementation, (2) implementation, and (3) implementation monitoring. We utilized a multifaceted implementation package consisting of discrete implementation strategies within each phase. In phase 1, we adapted questions from evidence-informed screening tools into a 21-item SSNAC questionnaire, and we used published frameworks to inform implementation readiness and process. In phases $2-3$, clinical staff deployed the SSNAC questionnaire to parents of CMC in-person or by phone as part of usual care and adapted to local clinical workflows. Staff used shared decision-making with parents and addressed identified needs by providing information about available resources, offering direct assistance, and making referrals to community agencies. Implementation outcomes included fidelity, feasibility, acceptability, and appropriateness.
\end{abstract}

Results: Observations from clinical staff characterized fidelity to use of the SSNAC questionnaire, assessment template, and shared decision-making for follow-up on unmet social needs. Levels of agreement (5-point Likert scale; $1=$ completely disagree; $5=$ completely agree) rated by staff for key implementation outcomes were moderate to high for acceptability (mean $=4.7$; range $=3-5$ ), feasibility ( mean $=4.2$; range $=3-5$ ), and appropriateness (mean $=4.6$; range $=4-5)$. 49 SSNAC questionnaires were completed with a 91\% response rate. Among participating parents, $37(76 \%)$ reported $\geq 1$ social need, including food/nutrition benefits (41\%), housing (18\%), and caregiver needs (29\%). Staff responses included information provision (41\%), direct assistance (30\%), and agency referral (30\%).

Conclusions: It was feasible for tertiary care center-based pediatric complex care programs to implement a standardized social needs assessment for CMC to identify and address parent-reported unmet social needs.

Keywords: Children with medical complexity, Social determinants of health, Implementation strategy, Complex care

\footnotetext{
${ }^{*}$ Correspondence: david.ming@duke.edu

1 Department of Pediatrics, DUMC, Duke University School of Medicine, Box 3352, Durham, NC 27710, USA

Full list of author information is available at the end of the article
}

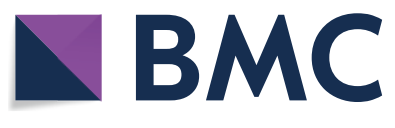

(c) The Author(s) 2021. Open Access This article is licensed under a Creative Commons Attribution 4.0 International License, which permits use, sharing, adaptation, distribution and reproduction in any medium or format, as long as you give appropriate credit to the original author(s) and the source, provide a link to the Creative Commons licence, and indicate if changes were made. The images or other third party material in this article are included in the article's Creative Commons licence, unless indicated otherwise in a credit line to the material. If material is not included in the article's Creative Commons licence and your intended use is not permitted by statutory regulation or exceeds the permitted use, you will need to obtain permission directly from the copyright holder. To view a copy of this licence, visit http://creativecommons.org/licenses/by/4.0/. The Creative Commons Public Domain Dedication waiver (http://creativeco mmons.org/publicdomain/zero/1.0/) applies to the data made available in this article, unless otherwise stated in a credit line to the data. 


\section{Contributions to the literature}

- In addition to supporting the intensive medical needs and high health service use by children with medical complexity (CMC), there is growing recognition that to advance health and well-being for all CMC, social needs must be addressed.

- Screening, assessment, and follow-up of social needs is important for children generally, yet these practices have not been adapted for CMC.

- We found that evidence-informed systematic social needs screening and assessment for CMC integrated into routine care was feasible.

- Our approach offers a practical blueprint that can be adapated by other pediatric complex care programs seeking to implement social needs screening and assessment.

\section{Background}

Children with medical complexity (CMC) are the subset of children and youth with special healthcare needs (CYSHCN) with the most intensive health needs [1]. CMC represent approximately $1 \%$ of all children, and their health-related costs are disproportionately high [2]. High health service utilization is a common consequence of the multiple chronic conditions, needs, and functional limitations (e.g., reliance on medical technology for daily living) that CMC experience [3]. Limited support available for primary care providers to coordinate care for CMC $[4,5]$, need for multi-specialty clinical care for each CMC [6], and high hospital utilization $[1,7]$ are why the locus of care for CMC is often the tertiary care center [2]: child-specific hospitals with highly specialized staff and technical expertise to which general and smaller, community-based care sites frequently refer patients with specialty needs [8]. For these reasons, a growing number of children's hospitals have developed pediatric complex care programs to facilitate care management, improve the care experience for CMC and their families, and reduce healthcare utilization and cost $[1,9]$.

Because of the multiple chronic co-morbidities faced by CMC, systems of care commonly approach this population's health needs with medically-focused interventions-e.g., scheduling specialty clinic appointments, medication reconciliation, and securing home medical supplies. While these interventions are essential aspects of care for CMC, a medically focused approach may overlook social needs that have at least as much-if not even greater-impact on the health of CMC [10]. Social need is a broad construct that can overlap with related domains, such as social drivers (or determinants) of health (SDH), adverse childhood experiences (ACEs), and parent/family health and well-being. The health of CMC is inseparable from that of their families [10] and the presence of adverse SDH-those SDH that negatively impact overall health-and/or ACEs are associated with worse health outcomes for children [11,12].

Given the importance of SDH to the overall health of children and CMC, social needs screening and intervention represents a potential opportunity to promote better overall health and well-being [13]. However, only a small number of validated, child-specific instruments have been published [14], and definitive evidence of positive impact of SDH screening and intervention on child health outcomes has not been clearly established [15]. While positive clinical trials of social needs screening and intervention have been conducted at primary care sites with previously healthy children [12, 16, 17], there has been little published evidence to-date about adaptation of these programs to the care of CMC. Although randomized controlled trials (RCT) of SDH screening and intervention specifically for $\mathrm{CMC}$ have not yet been conducted, implementation science methods are valuable within pre-RCT/pilot phase studies [18].

Despite these limitations of the evidence base, understanding how to implement SDH screening and intervention is critically important because there are growing system-level pressures from policymakers and payers to do so $[19,20]$. Child health systems in the United States (US) are shifting towards value-based care and payment-health care models that incentivize better quality, outcomes, and patient/family experience at lower $\cos t$ $[21,22]-$ and payers are beginning to mandate population-level SDH screening (e.g., North Carolina's statewide Medicaid managed care program) [23]. In such an evolving health care landscape increasingly focused on delivery of high-value care that addresses both social and medical drivers of health, a question of pragmatic relevance to child health systems and providers is: how can the existing evidence base be leveraged to inform implementation of SDH screening and intervention for high need, high cost patients such as CMC? To address this key question and advance the field, the primary aim of this study was to evaluate the feasibility of implementing evidence-informed social needs screening and assessment within pediatric complex care programs. Due to limited prospective studies of social needs screening within the pediatric complex care literature, our secondary aim was to measure unmet social needs reported by parents of CMC. 


\section{Methods}

\section{Design, setting, and participants}

This was a prospective, two-site feasibility study conducted between January 2019-July 2020 to implement evidence-informed systematic social needs screening and assessment within routine clinical care for CMC. The participating sites were established complex care programs for CMC with multi-specialty care based at pediatric tertiary care centers in the Southeastern US. Since their inception, the two sites have provided inpatient and outpatient care for over 300 patients to-date; one program's clinical care was more inpatient/hospitalfocused whereas the other program was more focused on the outpatient setting. Key features of both complex care programs included interdisciplinary clinical teams, care coordination, continuity of care, and direct patient care, all of which are common features of care delivery models for $\mathrm{CMC}$ [9]. A third complex care program participated in the development and implementation of the intervention. Since this third site did not collect implementation data, it is not included in this report.

Parents/caregivers (referred to as "parents") of CMC already receiving care from one of the two participating complex care programs were eligible to receive the systematic social needs assessment for CMC (SSNAC) intervention. Participants included a convenience sample of parents of eligible CMC who were approached by clinical staff as part of routine clinical care. CMC criteria were site-specific and consistent with existing operational criteria used by the two participating programs to define CMC (Additional file 1).

\section{Components of the systematic social needs assessment for CMC (SSNAC)}

Core components of the SSNAC intervention included using an evidence-informed questionnaire to screen for unmet needs, developing a structured approach for care team members to assess reported needs using shared decision-making, integration of assessment and followup into routine clinical care, and using multifaceted implementation strategies to facilitate overall implementation of the intervention.

\section{Screening Questionnaire development}

The SSNAC intervention consisted of implementing social needs screening and assessment for $\mathrm{CMC}$ at the two participating sites. A 21-item SSNAC questionnaire was integrated into each site's clinical workflow; items were adapted from existing social needs screening instruments (Accountable Health Communities HealthRelated Social Needs Screening Tool; NC Medicaid Standardized SDH Screening Questionnaire) [19, 24]. We selected these primary source instruments because their development was informed by published literature and a review of best practices, and they are being broadly implemented by policymakers and payers at the state (NC Medicaid) and national level (Centers for Medicare \& Medicaid Services), thus are highly relevant in our practice environment.

Adaptation of screening items was done by gathering direct feedback from clinical staff and parents. Each site's clinical staff ( $n=6$; one physician, one social worker or nurse, and one care coordinator per site) reviewed the proposed survey items and suggested site-specific adaptations before reaching verbal agreement on the final 21-item questionnaire. The questionnaire was pilot tested and cognitive interviews were conducted with five parents of CMC at each site. During pilot testing, parents reported that the items, overall, were appropriate and relevant. The questionnaire took approximately $30 \mathrm{~min}$ to administer in-person, and parent feedback informed changes in wording for multiple screener items. This combination of parent and clinical staff feedback resulted in refinement of the SSNAC questionnaire into the final version. The SSNAC questionnaire was administered by complex care program staff to parents of CMC. Questionnaires were built into an online survey and database system (REDCap) [25] and administered in-person or via phone.

\section{Assessment of social needs identified by screening questions}

When parents of CMC reported unmet social needs (i.e., "positive" response to $\geq 1$ items in the SSNAC questionnaire), a standardized approach guided complex care program staff's assessment and response. Assessment of reported unmet social needs was guided by a template developed in collaboration with long-standing partners from Legal Aid of North Carolina's statewide MedicalLegal Partnership program [26]. The assessment template was tailored to correspond with SSNAC screening questions and provided staff with the following approaches for response to unmet social needs: (a) providing information to families about how to meet the social need; (b) directly assisting the family with their social need; and/ or (c) making a direct referral to a community-based agency/partner with additional resources and expertise to meet the need. Specific questions prompted shared decision-making between clinical staff and parents to identify the social needs for which parents wanted immediate additional assistance.

\section{Implementation process}

SSNAC implementation followed three phases: (1) preimplementation planning, (2) implementation, and (3) implementation monitoring (Fig. 1). We mapped key 


\section{Systematic Social Needs Assessment for Children with Medical Complexity (SSNAC): Implementation Phases}

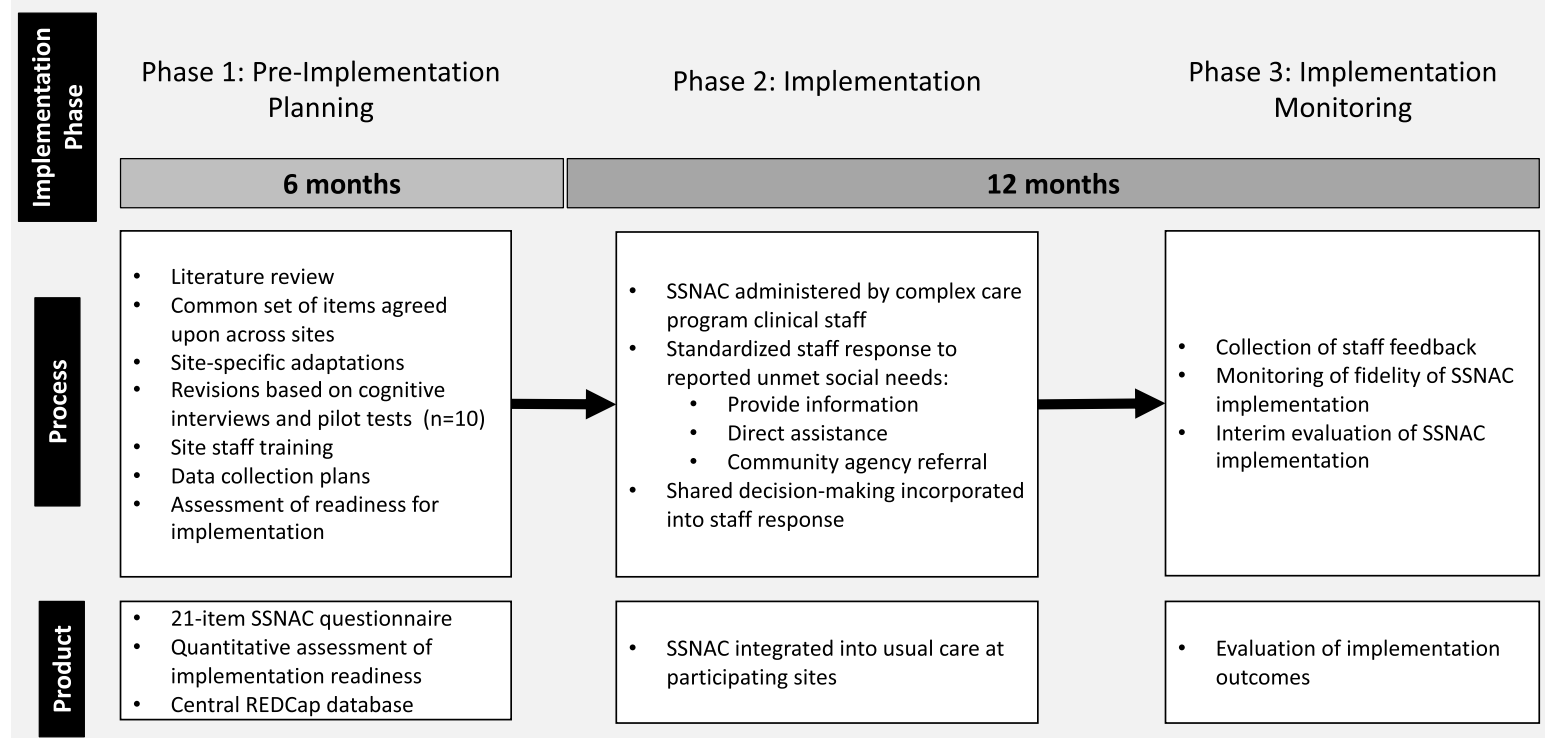

Fig. 1 Phases of systematic social needs assessment for CMC (SSNAC)

steps in the SSNAC implementation process to an evidence-based framework (Knowledge to Action) [27]. We utilized a multifaceted implementation package that consisted of multiple discrete, evidence-based implementation strategies [28] utilized in each project phase.

In the pre-implementation planning phase, we conducted a local needs assessment at each site consisting of assessment of implementation readiness, educational meetings with staff, and gathering feedback from parents. Prior to SSNAC implementation, multiple virtual educational planning meetings were held with staff from both sites to facilitate coalition building. SSNAC implementation readiness was measured with Hexagon Tool [29] ratings by clinical staff on a five-point Likert scale $(1=$ lowest; $5=$ highest). Mean ratings from eight respondents across both sites in six domains of implementation readiness were: evidence [4], usability (3.8), program supports (3.4), fit (4.6), need (3.4), and capacity (3.4). We used these responses to guide development of site-based workflows for the implementation phase.

In the implementation phase, the primary implementation strategy utilized was adaptation to tailor within local context. For example, complex care program staff that deployed the SSNAC questionnaire varied by site; one site utilized a clinical social worker while the other utilized a nurse care coordinator. Another example of adaptation was that in-person social needs screenings occurred either during clinic or hospital encounters in order to align with each participating complex care program's predominant clinical focus on outpatient or inpatient care. In-person screenings were initially the predominant approach at both sites; however, phone screenings became the primary modality subsequent to the onset of the COVID-19 pandemic in March 2020.

The implementation monitoring phase occurred concurrently with the implementation phase and continued through the end of the study. We measured fidelity by querying staff via online surveys following each SSNAC questionnaire for self-report of their use of the SSNAC questionnaire, use of the assessment template, and incorporation of shared decision-making. During this phase, we also regularly audited performance via monthly, open-ended surveys to further characterize real-world implementation from staff perspectives (e.g., usability of the questionnaire, challenges faced, parent feedback).

\section{Implementation outcomes}

Evidence-based implementation outcomes [30] included fidelity (degree to which SSNAC questionnaire was used as planned), feasibility (extent to which social needs assessment can be successfully carried out within complex care programs), acceptability (perception among program staff that social needs assessment was agreeable 
and satisfactory), and appropriateness (perceived fit/relevance of social needs assessment for complex care practice settings). Fidelity was measured by the following: (1) proportion of parents approached who completed SSNAC questionnaires and (2) staff self-report of use of the SSNAC questionnaire, shared decision-making, and assessment template for each completed screening, respectively. We measured feasibility, acceptability, and appropriateness outcomes by surveying clinical staff with validated instruments (4 items each rated on a 5-point Likert scale) at the end of the study period [31].

\section{Analyses}

Five respondents (out of 54) did not complete any social needs items and were removed to create a final sample size of 49 parent respondents. For analysis of implementation outcomes, survey responses from five clinical staff (out of six total) across the two sites were analyzed at the end of the study period to assess feasibility, acceptability, and appropriateness by calculating the mean and standard deviation per outcome. Staff responses to surveys upon completion of each SSNAC questionnaire were summarized to assess fidelity to SSNAC core components. For analysis of parent responses to the SSNAC questionnaire, reporting of unmet social needs included all participants except for items asked based on endorsement of a particular need, as noted in the corresponding table (Table 3). Responses to unmet needs were calculated for those parents who reported one or more unmet need. Descriptive statistics were calculated using proportions and frequencies for categorical variables and means and standard deviations for continuous variables. All analyses were completed using SAS v9.4. This study was classified as exempt by our institutional Internal Review Board.

\section{Results}

\section{Participant characteristics}

During the 12-month implementation phase, 49 CMC received the SSNAC intervention with $43 \%(n=21)$ at one site and $57 \%(n=28)$ at the second site. The average patient's age was 8.6 years old; $71 \%$ were Hispanic, Black, or multiracial; and $80 \%$ were publicly insured (Table 1 ). On average, seven distinct specialists were involved in each child's care and reliance on medical technology for daily living was common; the most prevalent medical devices were feeding tubes (82\%), supplemental oxygen $(35 \%)$, tracheostomy (22\%), and ventriculoperitoneal shunts (20\%). The vast majority of respondents (96\%) to the SSNAC questionnaire were parents and 53\% had some college or higher educational level. Fifty-six percent of parents reported household annual income of $\$ 40,000$ or less, the reported parental unemployment rate was
Table 1 Patient and parent characteristics

\begin{tabular}{ll}
\hline Variable & Overall \\
\hline$N$ & 49 \\
Patient demographic characteristics & \\
$\quad$ Patient age (years), mean (SD) & $8.6(5.8)$ \\
Patient race/ethnicity & \\
$\quad$ Black & $13(26.5 \%)$ \\
Hispanic & $20(40.8 \%)$ \\
White & $14(28.6 \%)$ \\
$\quad$ Multiracial or other & $2(4.1 \%)$ \\
Patient gender & \\
$\quad$ Male & $32(65.3 \%)$ \\
$\quad$ Female & $17(34.7 \%)$ \\
Public health insurance (Medicaid or Medicare) & $39(79.6 \%)$
\end{tabular}

Patient clinical characteristics

Specialists

(SD)

Number of specialists seen in past 12 months, mean 6.9 (2)

Neurology

Orthopedics

Pulmonary

Gastrointestinal

Otolaryngology

Pediatric general surgery

Ophthalmology

Cardiology

Endocrinology

Other specialist

Medical technology needs

Feeding tube

Oxygen

Tracheostomy

VP shunt

Ventilator

BiPAP

Central line

CPAP

Other

$39(79.6 \%)$

$28(57.1 \%)$

$28(57.1 \%)$

34 (69.4\%)

$27(55.1 \%)$

$24(49 \%)$

$21(42.9 \%)$

$21(42.9 \%)$

$20(40.8 \%)$

$45(91.8 \%)$

$40(81.6 \%)$

$17(34.7 \%)$

$11(22.4 \%)$

$10(20.4 \%)$

$5(10.2 \%)$

$4(8.2 \%)$

$3(6.1 \%)$

$2(4.1 \%)$

$18(36.7 \%)$

Parent/caregiver and household characteristics

Caregiver relationship to child

Parent or step-parent

$47(95.9 \%)$

Grandparent

$2(4.1 \%)$

Caregiver age (years), mean (SD)

$37.7(10.7)$

Caregiver gender

Male

$1(2 \%)$

Female

$48(98 \%)$

Caregiver education

Less than high school degree $\quad 10(20.4 \%)$

High school degree $\quad 13(26.5 \%)$

Some college or higher

$26(53.1 \%)$

Caregiver employment status

Employed full time

$10(20.4 \%)$ 
Table 1 (continued)

\begin{tabular}{|c|c|}
\hline Variable & Overall \\
\hline Employed part time & $5(10.2 \%)$ \\
\hline Homemaker & $17(34.7 \%)$ \\
\hline Retired & $3(6.1 \%)$ \\
\hline Unemployed & $9(18.4 \%)$ \\
\hline Other & $5(10.2 \%)$ \\
\hline \multicolumn{2}{|l|}{ Household annual income ${ }^{\mathrm{a}}(n=32)$} \\
\hline Less than $\$ 20,000$ per year & $9(28.1 \%)$ \\
\hline$\$ 20,001-\$ 40,000$ per year & $9(28.1 \%)$ \\
\hline$\$ 40,001-\$ 60,000$ per year & $7(21.9 \%)$ \\
\hline$\$ 60,001-\$ 80,000$ per year & $4(12.5 \%)$ \\
\hline More than $\$ 80,000$ pe year & $3(9.4 \%)$ \\
\hline Number of household members, mean (SD) & $4.0(1.4)$ \\
\hline Household crowding index, median (Q1, Q3) & $1.3(1.0,1.7)$ \\
\hline \multicolumn{2}{|l|}{ Home community rural/urban status ${ }^{\mathrm{b}}$} \\
\hline Urban focused & $34(69.4 \%)$ \\
\hline Large/small/isolated small rural city/town focused & $10(30.6 \%)$ \\
\hline
\end{tabular}

a 17 respondents did not complete the income question and were excluded from this denominator

${ }^{b}$ Based on the Rural Urban Commuting Area (RUCA) classification using home zip code

Abbreviations: CPAP continuous positive airway pressure, BiPAP bilevel positive airway pressure, $V P$ ventriculoperitoneal

$18 \%$, the average household size was four people, and $69 \%$ reported living in urban home communities.

\section{Implementation outcomes}

Fidelity from the parent perspective was high-98\% of parents approached by program staff agreed to initiate the SSNAC questionnaire. Among the 49 parents who initiated the questionnaire, $91 \%$ completed all social needs screening items. High levels of fidelity to the core components of the SSNAC intervention were also observed from the staff perspective with clinical staff reporting use of the SSNAC questionnaire in 100\% of screenings and use of shared decision-making $92 \%$ of the time to identify social needs for which additional assistance was requested (Table 2). Clinical staff used the assessment template to guide their response for $95 \%$ of parents who reported $\geq 1$ unmet social need.

Staff generally found SSNAC implementation to be feasible, acceptable, and appropriate. Levels of agreement (5-point Likert scale; $1=$ completely disagree; $5=\mathrm{com}$ pletely agree) rated by staff survey responses were moderate to high for acceptability $($ mean $=4.7$; range $=3-5$ ), feasibility (mean $=4.2$; range $=3-5$ ), and appropriateness $($ mean $=4.6$; range $=4-5$ ). Additionally, open-ended feedback from clinical staff provided further insight into the SSNAC questionnaire's acceptability to parents and overall usability and implementation. First, staff reported
Table 2 Implementation outcomes

\begin{tabular}{llll}
\hline Variable & Overall & Site A & Site B \\
\hline$N$ & 49 & 21 & 28 \\
Fidelity; $n$ (\%) & & & \\
$\quad$ Staff use of SSNAC to identify social needs & & \\
$\quad$ Yes & $49(100 \%)$ & $21(100 \%)$ & $28(100 \%)$ \\
Staff use of shared decision-making to assist with social needs \\
$\quad$ Yes & $45(91.8 \%)$ & $19(90.5 \%)$ & $26(92.9 \%)$ \\
$\quad$ Not applicable, no needs & $4(8.2 \%)$ & $2(9.5 \%)$ & $2(7.1 \%)$ \\
identified & & & \\
Staff use of assessment framework to respond to unmet social needs \\
$\quad$ Yes & $26(53.1 \%)$ & $14(66.7 \%)$ & $12(42.9 \%)$ \\
$\quad$ Not applicable, no needs iden- & $23(46.9 \%)$ & $7(33.3 \%)$ & $16(57.1 \%)$ \\
tified or parent/caregiver declined & & & \\
assistance & & & \\
Feasibility*; mean (range) & $4.2(3-5)$ & \\
Acceptability*; mean (range) & $4.7(3-5)$ & \\
Appropriateness*; mean (range) & $4.6(4-5)$ &
\end{tabular}

*Measured by implementation survey of staff at both sites; site-specific $n$ 's and values suppressed due to small cell size ( $n=5$ total)

that the questionnaire was straightforward, the items were clear and easily understood, and overall, parents were receptive to the questionnaire. Second, in-person deployment was preferred by staff instead of phone; a conversational approach to deployment of the questionnaire increased parents' comfort level and facilitated individualized discussions about social stressors stemming from the COVID-19 pandemic. Finally, flexible approaches by staff facilitated integration of the questionnaire within routine clinical encounters (e.g., conducting questionnaire before physician entered clinic exam room; screening patients in the hospital before discharge; using telehealth video visits).

\section{Social needs reported by parents}

Overall, 76\% of parent respondents reported $\geq 1$ unmet social need (Table 3$)$. Thirty-seven percent $(n=18)$ requested additional assistance to address reported needs. Among the 37 parents who reported at least 1 unmet social need, $41 \%$ received additional information, 30\% received direct assistance, and 30\% were referred to a community-based agency for additional asssistance (Table 3).

\section{Discussion}

In this multi-site prospective study, implementation of evidence-informed social needs screening and assessment for CMC was feasible. Several observations supported implementation feasibility. First, fidelity to the core components of the SSNAC intervention was high, as evidenced by universal use of the SSNAC questionnaire to identify needs and $92 \%$ reported use 
Table 3 Social needs reported by CMC caregivers and program follow-up responses to those needs

\begin{tabular}{ll}
\hline Variable & Overall \\
\hline$N$ & 49 \\
Any unmet social needs & \\
$\quad$ No & $12(24.5 \%)$ \\
Yes & $37(75.5 \%)$ \\
Categories of unmet social need & \\
$\quad$ Gaps in access to food and/or nutrition benefits & $20(40.8 \%)$ \\
$\quad$ Food insecurity, including formula & $17(34.7 \%)$ \\
$\quad$ Gap in federal nutritional benefits & $8(16.3 \%)$ \\
Housing-related concerns & $9(18.4 \%)$ \\
$\quad$ Housing insecurity & $3(6.1 \%)$ \\
$\quad$ Housing environmental safety concerns & $6(12.2 \%)$ \\
$\quad$ Gap in home utility services & $4(8.2 \%)$ \\
Lack of medical transportation & $6(12.2 \%)$ \\
Concerns about school services ${ }^{\text {a }}(n=35)$ & $8(22.9 \%)$ \\
$\quad$ Gap in supplemental security income benefits ${ }^{\mathrm{b}}(n=11)$ & $8(72.7 \%)$ \\
$\quad$ Gap in home and community-based services pro- & $8(80 \%)$ \\
gram waiver $(n=10)$ & $1(2 \%)$ \\
Interpersonal safety concerns & $14(28.6 \%)$ \\
Any caregiver needs & $9(18.4 \%)$ \\
$\quad$ High caregiver burden & $7(14.3 \%)$ \\
$\quad$ Caregiver social isolation & $5(10.2 \%)$ \\
Urgent social needs reported & $18(36.7 \%)$
\end{tabular}

\section{Follow-up response by complex care programs to address social} needs ${ }^{\mathrm{d}}$

$N$

Provided information, referrals, or direct assistance

Provided information to patient/family

Referral made to community-based partner/agency

Direct assistance to patient/family

37

$20(54.1 \%)$

$15(40.5 \%)$

$11(29.7 \%)$

$11(29.7 \%)$

Sample size varies if item was only asked of a subset of participants

a Among children with an IEP (individualized education program) or 504 plan

${ }^{\mathrm{b}}$ Among those waiting to hear back about an SSI (supplemental security income) application or if application was recently denied

' Among those waiting to hear back about CAP/C (Community Alternatives Program for Children is the Medicaid Home and Community-Bsaed Services waiver program in North Carolina) application or if application was recently denied

${ }^{d}$ Among those with at least one unmet social need

of SDM by clinical staff to align assessment with parent preferences. We hypothesize that this high level of fidelity reflected high stakeholder engagement and readiness to implement, as demonstrated by high preimplementation ratings on the Hexagon Tool analysis. Second, this favorable implementation climate was likely fostered and feasibility was strengthened by integrating the SSNAC intervention into existing complex care program clinical operations. This pragamatic approach allowed for implementation without need for new clinical staff; in turn, this allowed for the SSNAC intervention to be budget neutral and the questionnaire to be deployed by experienced clinical staff at each site with established, therapeutic patient-clinician relationships. Finally, feasibility was supported by staff open-ended feedback and responses to evidence-based quantitative measures of implementation outcomes (feasibility, acceptability, appropriateness) [31].

Discrete implementation strategies used in different project phases contributed to successful implementation. In particular, efforts during the pre-implementation phase were key. In-depth efforts to engage with staff at both sites during the pre-implementation phase via virtual educational meetings helped to establish a sense of collaboration as a local coalition. The shared goals for the project were further facilitated by gathering feedback from site staff and parents of CMC to tailor evidence-informed social needs screening items into a final SSNAC questionnaire that was acceptable for all. Working together across sites on pre-implementation planning steps help to establish a favorable baseline implementation climate with engaged and committed stakeholders. As such, the pre-implementation phase would be critical to replicate SSNAC at future implementation sites.

During the subsequent implementation phase, the favorable implementation climate likely contributed to clinical staff's willingness to develop flexible adaptations when confronted with real-world implementation challenges-e.g., incorporating SSNAC questionnaires into busy clinical practice settings and pivoting to virtual questionnaire deployment during the COVID-19 pandemic-thus, further facilitating fidelity to the intervention over time. Flexibility to adapt and tailor the approach to each site's staffing model-e.g., use of social worker or a nurse for questionnaire deployment-allowed for the SSNAC intervention to best fit into existing clinical workflows.

Shared decision-making (SDM) is recommended as a patient-centered approach that stresses the patient/ family's desire for additional assistance, efficiently aligns patient/family preferences with available resources and is associated with higher rates of referral to address unmet needs [32, 33]. However, few prior social needs screening interventions have specifically incorporated SDM [12]. We were unable to characterize the specific reasons why $63 \%$ of parents of CMC declined additional assistance in our study, despite reporting high prevalence of unmet social needs. Potential explanations may include (1) concurrent access to additional support via parent-parent advice-giving and informal communication networks [34]; (2) negative prior experiences accessing or working with social support programs (e.g., food pantry, respite services); and/or (3) mistrust of programs and resources 
based on negative experiences for many families stemming from systematic barriers to accessing care, personal discrimination, and systemic racism [35].

\section{Strengths}

This study had several strengths. First was the realworld implementation of SSNAC at multiple sites. Flexible approaches that utilized existing clinical staff to deploy the SSNAC questionnaire within routine clinical care facilitated implementation in different contexts. Second, we incorporated evidence-based methodse.g., implementation frameworks and outcomes measurement-that generated insights into the real-world implementation process of social needs screening and intervention [12, 36]. Finally, incorporation of a structured assessment template that included prompts for the use of SDM helped to align staff response to social needs with the priorities and preferences of parents. Though low levels of parental request for additional assistance with needs could have been a negative reflection of the SSNAC process, positive parent feedback during pilot testing of the questionnaire and favorable staff observations during the implementation phase highlighted the perceived value and relevance of SSNAC to parents. For example, several parents appreciated being asked specifically about caregiver burden and social isolation during conversations with the clinical staff. The conversational nature reported by staff when implementing the SSNAC questionnaire within routine encounters may have strengthened relationships with parents by signaling that social needs were just as important for each child's overall health and well-being as medical needs.

\section{Limitations}

Several limitations of this study should be acknowledged. One category of limitations stems from unique aspects of our implementation environment. Generalizability is limited because SSNAC was implemented within complex care programs that cared for CMC with higher levels of complexity than CMC in peer programs-e.g., higher prevalence of feeding tubes, supplemental oxygen, tracheostomy, and ventriculoperitoneal shunts [37]. However, as the CMC population grows and the number of complex care programs increases [1], opportunities to apply the core components of SSNAC are growing. Generalizability is also limited for clinical settings without dedicated staff who have continuity of care and longterm relationships with families. In our sites, family/clinician relationships forged over time created a foundation of mutual trust that may have made parents more comfortable with disclosing social needs. Furthermore, particularly close, long-standing working relationships with our collaborators from Legal Aid of North Carolina's
Medical-Legal Partnership (MLP) program represented a unique asset within our environment. The role of MLPs in pediatrics is well-described [38], and we encourage other sites to explore strengthening partnerships with this valuable community-based organization. Finally, SSNAC required clinical staff to deploy the questionnaire. Models of care for CMC are heterogeneous [9] and not every program has existing staff available for social needs screening and assessment. However, our experience utilizing different types of staff (e.g., nurse, social worker) based on each site's resources and capacity coupled with published social needs screening in non-CMC populations by non-clinical community health workers [17] suggest that staffing models can be flexible.

A second category of limitations is related to methodological considerations. First, we did not measure distal process (e.g., receipt of services) or health outcomes (e.g., quality of life, parent well-being) and focused primarily on implementation outcomes. Balancing pragmatism and methodological rigor is common in social needs research; therefore, implementation science and quality improvement methods are recommended over traditional efficacy trial designs [12]. Second, we did not use a validated scale to measure staff-reported SDM and we were unable to directly measure parent perspectives on SDM. Third, though items in the SSNAC questionnaire were drawn from those described in the published literature, the final questionnaire's items in its fully implemented form were not validated and some terms (e.g. caregiver burden) reflected a deficits-based framework [39]. Strengths-based approaches better highlight parents' and families' assets available to address social needs rather than highlighting their deficits via the use of terms such as "burden." However, multi-site consensus building, pilot testing with families of $\mathrm{CMC}$, and alignment with forthcoming state-level Medicaid requirements for SDH screening [24] increased the usability and relevance of the final selected SSNAC items. Given the wide range of SDH screening instruments that are currently being used by pediatric providers, many of which are not validated [33], the specific survey selected arguably may be less important than building capacity to facilitate parent/ family engagement, shared decision-making, and followup on identified needs [32].

\section{Future directions}

Future research can build on these findings by implementing systematic social needs screening and assessment at additional clinical sites in order to understand (1) how to adapt the intervention's core components for varied local contexts, (2) comparative effectiveness of different strategies for questionnaire implementation (e.g., in-person vs phone vs telehealth), (3) cost-effectiveness 
of various approaches, and (4) impacts on downstream health outcomes. Given the high prevalence of social needs among CMC and growing recognition of the importance of the intersection between medical and social needs by patients, providers, health systems, and payers, it will be critical to augment existing complex care models to better address social needs as a mechanism to enhance long-term health and well-being.

\section{Conclusion}

It was feasible for pediatric complex care programs to implement systematic social needs screening and assessment to identify unmet social needs among CMC. A similar intervention can be considered for adaptation and implementation by other programs that care for CMC. Doing so can further demonstrate how to incorporate implementation science methods and clinical care in order to address social needs and advance health for vulnerable child populations.

\begin{abstract}
Abbreviations
SSNAC: Systematic social needs assessment for children with medical complexity; SDH: Cocial drivers (determinants) of health; CMC: Children with medical complexity; CYSHCN: Children and youth with special healthcare needs; EHR: Electronic health record; SDM: Shared decision-making; NC: North Carolina.
\end{abstract}

\section{Supplementary Information}

The online version contains supplementary material available at https://doi. org/10.1186/s43058-021-00237-3.

Additional file 1. Criteria to define children with medical complexity (CMC).

\section{Acknowledgements}

The authors acknowledge Savithri Nageswaran, MD, MPH; Aura Rosado, MSW; and Vanessa Ortiz, EMT-B from the Pediatric Enhanced Care Program (Wake Forest School of Medicine) for their role in helping to develop the SSNAC intervention. The authors also acknowledge Victoria Parente, MD, MPH, for her contributions during the pre-implementation phase of the study.

\section{Authors' contributions}

DM and NdJ conceptualized and designed the manuscript; collected, analyzed, and interpreted data; drafted the initial manuscript; reviewed and revised the manuscript; and approved the final manuscript as submitted. KJ analyzed and interpreted data; reviewed and revised the manuscript; and approved the final manuscript as submitted. SD, ES, HT, and AC collected data; reviewed and revised the manuscript; and approved the final manuscript as submitted. MM contributed to conceptualization and design of the study; reviewed and revised the manuscript; and approved the final manuscript as submitted.

\section{Funding}

Dr. Ming's contributions for this study were supported by the National Institutes of Health, National Heart, Lung, and Blood Institute [K12HL13830]. Dr. deJong's contributions for this study were supported by the National Center for Advancing Translational Sciences, National Institutes of Health, through Grant KL2TR002490. The content is solely the responsibility of the authors and does not necessarily represent the official views of the $\mathrm{NIH}$.

\section{Availability of data and materials}

The datasets used and/or analyzed during the current study are available from the corresponding author on reasonable request.

\section{Declarations}

Ethics approval and consent to participate

This study was classified as exempt and approved by the Duke Health Internal Review Board

\section{Consent for publication}

Not applicable-individual personal data not presented in this study.

\section{Competing interests}

The authors declare that they have no competing interests.

\section{Author details}

'Department of Pediatrics, DUMC, Duke University School of Medicine, Box 3352, Durham, NC 27710, USA. ${ }^{2}$ Department of Medicine, Duke University School of Medicine, 2301 Erwin Rd, Durham, NC 27710, USA. ${ }^{3}$ Department of Population Health Sciences, Duke University School of Medicine, 215 Morris St, Durham, NC 27701, USA. ${ }^{4}$ Department of Pediatrics, University of North Carolina School of Medicine, 260 MacNider Building, CB\#7220, Chapel Hill, NC 27599, USA. ${ }^{5}$ University of North Carolina School of Public Health, 135 Dauer Drive, Chapel Hill, NC 27599, USA. ${ }^{6}$ Legal Aid of North Carolina, 224 S. Dawson St, Raleigh, NC 27601, USA

Received: 4 January 2021 Accepted: 5 November 2021

Published online: 21 November 2021

\section{References}

1. Cohen E, Berry JG, Sanders L, Schor EL, Wise PH. Status complexicus? The Emergence of Pediatric Complex Care. Pediatrics. 2018;141(Suppl 3):S202-S11.

2. Kuo DZ, Houtrow AJ. Council On Children With D. Recognition and management of medical complexity. Pediatrics. 2016;138(6):e20163021

3. Cohen E, Kuo DZ, Agrawal R, Berry JG, Bhagat SK, Simon TD, et al. Children with medical complexity: an emerging population for clinical and research initiatives. Pediatrics. 2011;127(3):529-38.

4. Okumura MJ, Knauer HA, Calvin KE, Takayama J. Pediatricians' comfort level in caring for children with special health care needs. Acad Pediatr. 2017;17(6):678-86

5. Foster CC, Mangione-Smith R, Simon TD. Caring for children with medical complexity: perspectives of primary care providers. J Pediatr. 2017;182(275-82):e4.

6. Cohen E, Berry JG, Camacho X, Anderson G, Wodchis W, Guttmann A Patterns and costs of health care use of children with medical complexity. Pediatrics. 2012;130(6):e1463-70.

7. Berry JG, Agrawal R, Kuo DZ, Cohen E, Risko W, Hall M, et al. Characteristics of hospitalizations for patients who use a structured clinical care program for children with medical complexity. J Pediatr. 2011;159(2):284-90.

8. Hensher MPM, Adomakoh S. Referral Hospitals. In: Jamison DTBJ, Measham AR, et al., editors. Disease control priorities in developing countries. 2nd. ed. New York: Oxford University Press; 2006.

9. Pordes E, Gordon J, Sanders LM, Cohen E. Models of care delivery for children with medical complexity. Pediatrics. 2018;141(Suppl 3):S212-S23.

10. Barnert ES, Coller RJ, Nelson BB, Thompson LR, Klitzner TS, Szilagyi M, et al. A healthy life for a child with medical complexity: 10 domains for conceptualizing health. Pediatrics. 2018;142(3).

11. Johnson SB, Riley AW, Granger DA, Riis J. The science of early life toxic stress for pediatric practice and advocacy. Pediatrics. 2013;131(2):319-27.

12. Beck AF, Cohen AJ, Colvin JD, Fichtenberg CM, Fleegler EW, Garg A, et al. Perspectives from the Society for Pediatric Research: interventions targeting social needs in pediatric clinical care. Pediatr Res. 2018;84(1):10-21.

13. Garg A, Homer CJ, Dworkin PH. Addressing social determinants of health: challenges and opportunities in a value-based model. Pediatrics. 2019;143(4):e20182355. 
14. Sokol R, Austin A, Chandler C, Byrum E, Bousquette J, Lancaster C, et al. Screening children for social determinants of health: a systematic review. Pediatrics. 2019;144(4):e20191622.

15. Bickerdike L, Booth A, Wilson PM, Farley K, Wright K. Social prescribing: less rhetoric and more reality. a systematic review of the evidence. BMJ Open. 2017;7(4):e013384.

16. Garg A, Toy S, Tripodis Y, Silverstein M, Freeman E. Addressing social determinants of health at well child care visits: a cluster RCT. Pediatrics. 2015:135(2):e296-304

17. Gottlieb LM, Hessler D, Long D, Laves E, Burns AR, Amaya A, et al. Effects of social needs screening and in-person service navigation on child health: a randomized clinical trial. JAMA Pediatr. 2016;170(11):e162521.

18. Taylor SP, Kowalkowski MA. Using implementation science-guided pilot studies to assess and improve the informativeness of clinical trials. J Gen Intern Med. 2021;36(2):533-6.

19. Billioux A, Verlander K, Anthony S, Alley D. Standardized screening for health-related social needs in clinical settings: the accountable health communities screening tool. Discussion paper, vol. 2017. Washington, DC: National Academy of Medicine; 2017.

20. Wortman Z, Tilson EC, Cohen MK. Buying health for North Carolinians: addressing nonmedical drivers of health at scale. Health Aff (Project Hope). 2020;39(4):649-54.

21. Wong CA, Perrin JM, McClellan M. Making the case for value-based payment reform in children's health care. JAMA Pediatr. 2018;172(6):513-4.

22. Langer CS, Antonelli RC, Chamberlain L, Pan RJ, Keller D. Evolving federal and state health care policy: toward a more integrated and comprehensive care-delivery system for children with medical complexity. Pediatrics. 2018;141(Suppl 3):S259-S65.

23. Cohen MK. North Carolina's transformation to Medicaid managed care. N C Med J. 2019:80(5):277-9.

24. Services NCDoHaH. Using standardized social determinants of health screening questions to identify and assist patients with unmet healthrelated resource needs in North Carolina. North Carolina Department of Health and Human Services; 2018. April 5, 2018.

25. Harris PA, Taylor R, Thielke R, Payne J, Gonzalez N, Conde JG. Research electronic data capture (REDCap)--a metadata-driven methodology and workflow process for providing translational research informatics support. J Biomed Inform. 2009;42(2):377-81.

26. deJong NA, Kimple KS, Morreale MC, Hang S, Davis D, Steiner MJ. A quality improvement intervention bundle to reduce 30-day pediatric readmissions. Pediatr Qual Saf. 2020;5(2):e264.

27. Field B, Booth A, llott I, Gerrish K. Using the Knowledge to Action Framework in practice: a citation analysis and systematic review. Implement Sci. 2014;9:172.
28. Powell BJ, Waltz TJ, Chinman MJ, Damschroder LJ, Smith JL, Matthieu MM, et al. A refined compilation of implementation strategies: results from the Expert Recommendations for Implementing Change (ERIC) project. Implement Sci. 2015;10:21.

29. Metz ALL. The Hexagon Tool: Exploring Context. Chapel Hill, NC: National Implementation Research Network, Frank Porter Graham Child Development Institute: University of North Carolina at Chapel Hill; 2019.

30. Proctor E, Silmere H, Raghavan R, Hovmand P, Aarons G, Bunger A, et al. Outcomes for implementation research: conceptual distinctions, measurement challenges, and research agenda. Adm Policy Ment Health. 2011;38(2):65-76.

31. Weiner BJ, Lewis CC, Stanick C, Powell BJ, Dorsey CN, Clary AS, et al. Psychometric assessment of three newly developed implementation outcome measures. Implement Sci. 2017;12(1):108.

32. Garg A, Boynton-Jarrett R, Dworkin PH. Avoiding the unintended consequences of screening for social determinants of health. Jama. 2016;316(8):813-4.

33. Garg A, Sheldrick RC, Dworkin PH. The inherent fallibility of validated screening tools for social determinants of health. Acad Pediatr. 2018;18(2):123-4.

34. Rafferty KA, Beck GA. "You Are Not Alone": advice giving for parents of children living with complex chronic conditions. Health Commun. 2020;35(11):1386-95.

35. Trent M, Dooley DG, Douge J, Section On Adolescent H, Council On Community P, Committee On A. The impact of racism on child and adolescent health. Pediatrics. 2019;144(2):e20191765.

36. Gottlieb L, Cottrell EK, Park B, Clark KD, Gold R, Fichtenberg C. Advancing social prescribing with implementation science. J Am Board Fam Med. 2018;31(3):315-21.

37. Kuo DZ, Berry JG, Glader L, Morin MJ, Johaningsmeir S, Gordon J. Health services and health care needs fulfilled by structured clinical programs for children with medical complexity. J Pediatr. 2016;169:291-6 e1.

38. Murillo SN, Rosenthal A, Fenick AM, Keene D. The impact of a pediatric medical-legal partnership on pediatric providers. Acad Pediatr. 2021;S1876-2859(21)00360-0.

39. Comeau M. Family burden and medical complexity: wrestling with the meaning and impact of commonly used terms. Palo Alto: Lucile Packard Foundation for Children's Health; 2019. June 18, 2019

\section{Publisher's Note}

Springer Nature remains neutral with regard to jurisdictional claims in published maps and institutional affiliations.
Ready to submit your research? Choose BMC and benefit from:

- fast, convenient online submission

- thorough peer review by experienced researchers in your field

- rapid publication on acceptance

- support for research data, including large and complex data types

- gold Open Access which fosters wider collaboration and increased citations

- maximum visibility for your research: over $100 \mathrm{M}$ website views per year

At BMC, research is always in progress.

Learn more biomedcentral.com/submissions 